\title{
Microwave-induced acetylation of some aromatic primary amines using acetic acid
}

\author{
K. L. Ameta and B. L. Verma* \\ Department of Chemistry, Faculty of Science, M. L. Sukhadia University, Udaipur-313 002, India \\ E-mail : verma_bl@yahoo.com_Fax : 91-0294-461933 \\ Manuscript received 2 April 2001, revised 17 April 2002, accepted 23 May 2002
}

\begin{abstract}
Microwave-induced synthesis of anilides from aromatic primary amines using acetic acid with considerable reaction rate enhancement and improved yields is reported.
\end{abstract}

Acetylation of aromatic primary amines ${ }^{1}$ is generally carried out by using acetic anhydride. Acetic acid in presence or absence of zinc dust can also be used for the conversion of aniline to acetanilide. However, the method requires high temperature, gas trap and $1.5 \mathrm{~h}$ refluxation.

In view of the above and wide applicability of microwave irradiation in chemical reaction enhancement ${ }^{2}$, we report here the microwave-induced synthesis of anilides from some substituted primary aromatic amines using acetic acid and in the absence of zinc dust resulting higher yields, clear reaction products and easier workup. The results are presented in Table 1.

\begin{tabular}{lccccc}
\hline \multicolumn{5}{c}{ Table 1. Results of } & \multicolumn{5}{c}{ microwave enhanced acetylation by acetic acid } \\
SI & Substrate & Product & Time & Yield & M.p.* \\
no. & & & min & $\%$ & ${ }^{0} \mathrm{C}$ \\
1. & Aniline & Acetanilide & 10 & 85 & 114 \\
2. & $o$-Toluidine & $o$-Methylacetanilide & 15 & 65 & 110 \\
3. & $m$-Toluidine & $m$-Methylacetanilide & 15 & 85 & 65 \\
4. & $p$-Toluidine & $p$-Methylacetanilide & 15 & 90 & 148 \\
5. & 2,4-Dimethylaniline & 2,4-Dimethylacetanilide & 15 & 80 & 127 \\
6. & $p$-Anisidine & $p$-Methoxyacetanilide & 15 & 71 & 127 \\
7. & $p$-Bromoaniline & $p$-Bromoacetanilide & 20 & 70 & 167 \\
8. & $p$-Nitrophenol & $p$-Nitrophenylacetate & 18 & 86 & 81 \\
9. & $p$-Nitroaniline & $p$-Nitroacetanilide & 18 & 76 & 212 \\
10. & $\alpha$-Napthylamine & $\alpha$-Napthylamineacetate & 18 & 74 & 159 \\
"Lit. ${ }^{3}$ m.p. & & & & \\
\hline
\end{tabular}

\section{Experimental}

M.ps. were taken in open capillary on an electrically heated metal block and are uncorrected. The reactions were carried out in a domestic Kenstar MO 9706 microwave oven (output energy, $1200 \mathrm{~W}$; frequency, $2450 \mathrm{MHz}$ ).

General procedure : A solution of amine $(0.054 \mathrm{~mol})$ in glacial acetic acid $(10.0 \mathrm{ml})$ was taken in a $100-\mathrm{ml}$ Erlenmeyer flask fitted with a funnel as a loose top. The reaction mixture was then irradiated under microwave (17-30\% power) for $2 \mathrm{~min}$. Then an interval of $1 \mathrm{~min}$ was allowed to avoid excessive evaporation of the solvent. This protocol was repeated until reaching an overall irradiation time of 10-20 min. It was then cooled and the resulting solution was poured in ice-cold water. In the case of substrate Sl. nos. 1, 3, 5, 6 and 8 (Table 1), the acetates separated during the course of reaction. The resulting solid was filtered, washed with water and recrystallized from alcohol. The products were characterized by m.p., co-TLC and superimposable IR-spectra of the authentic samples.

\section{Acknowledgement}

The authors are highly thankful to Head, Department of Chemistry, M. L. Sukhadia University. Udaipur, for facilities.

\section{References}

I. A. I. Vogel. "Elementary Practical Organic Chemistry. Part I. Small Scale Preparations", 2nd. ed.. ELBS, London, 1972.

2. S. Caddick. Tetrahedron, 1995, 51, 10403; A. K. Bose, B. K. Banik, N. Lavlinskaia, M. Jayaraman and M. S. Manhas, Chemtech., 1997, 27, 18; D. M. P. Mingos and D. R. Baghurst, Chem. Soc. Rev., 1991. 20, 1; S. A. Galema. Chem. Soc. Rev., 1997, 26, 233; A. K. Mitra, A. De and N. Karchaudhuri, J. Indian Chem. Soc., 1999, 76, 218.

3. H. Middleton, "Systematic Quantitative Organic Analysis", Edward Arnold, London, 1956. 